\title{
Representational Trajectories in the Understanding of Mendelian Genetics
}

\author{
Fernando Flores-Camacho ${ }^{{ }^{*}}$, Elena Calderón-Canales ${ }^{1 * *}$, Beatriz García-Rivera ${ }^{1}$, \\ Leticia Gallegos-Cázares ${ }^{1}$, Araceli Báez-Islas ${ }^{1}$ \\ ${ }^{1}$ Instituto de Ciencias Aplicadas y Tecnología, Universidad Nacional Autónoma de México, Circuito Exterior S/N, Ciudad \\ Universitaria, 04510, Mexico City, MEXICO
}

Received 18 January 2021 - Accepted 7 June 2021

\begin{abstract}
Understanding genetics is one of the most significant learning difficulties faced by students. To improve teaching genetics and the students' representational competence within the classroom have been proposed using multiple representations. This study presents an analysis of representational levels used by high school students learning Mendelian genetics and determining the construction trajectories of these representations. An assessment instrument was used to analyse the representational levels of 186 students with three different teaching strategies. The levels were used to analyse and classify students' answers, written texts, and drawings and diagrams. The result shows that learning Mendelian genetics is a gradual process in which students appeal to various levels of representations that can determine different trajectories and demonstrate progress on comprehension. We identify five trajectories, ranging from responses that rely on descriptions of observable traits to responses from students who could integrate processes or use models.
\end{abstract}

Keywords: genetics, multiple representations, biology education, competences, learning

\section{INTRODUCTION}

Genetics is the cornerstone of modern biology; its comprehension is essential to student's education due to its scientific importance and social relevance. Like the rest of society, students must acquire a basic knowledge of this subject to understand its implications and make informed decisions (Jalmo \& Suwandi, 2018).

Research has shown that students from different educational levels consider genetics one of the most cumbersome educational topics and often have a poor knowledge base and several misconceptions. Some authors ascribe this difficulty to the intricacies of integrating multiple levels of biological organisation (Banet \& Ayuso, 2000; Chattopadhyay, 2005; Duncan \& Reiser, 2007; Duncan, Castro-Faix, \& Choi, 2016; Lewis \& Wood-Robinson, 2000; Lewis, Leach, \& Wood-Robinson, 2000a, 2000b, 2000c; Marbach-Ad \& Stavy, 2000). Others find that students' misconceptions result from the conceptualisation of genes as a passive particle that passes from generation to generation (Venville \& Treagust, 1998).
Knippels (2002) grouped learning difficulties in genetics into five categories: 1) vocabulary and terminology, 2) the mathematical content of Mendelian tasks, 3) the cytological process, 4) the abstract nature of the content and its sequence within the curricula, and 5) the complexity of transitioning between micro and macro levels. The last category also includes two significant difficulties that other authors have acknowledged: a) genetic phenomena are nonobservable, complicating the understanding of processes that involve entities that are invisible to the naked eye and allow of no direct experimentation (Gilbert, Osborne, \& Fensham, 1982; Kapteijn,1990) and b) it is hierarchically organised, which hampers the understanding that the micro-levels relate to more complex processes, i.e. micro-interactions lead to macro interactions (Marbach-Ad \& Stavy, 2000). As Griffiths and Stotz (2013) point out, a more profound difficulty originates because gene models involve different instrumental and epistemological positions that students do not perceive and are the source of many misconceptions.

(c) 2021 by the authors; licensee Modestum. This article is an open access article distributed under the terms and conditions of the Creative Commons Attribution License (http://creativecommons.org/licenses/by/4.0/). 


\section{Contribution to the literature}

- The study presents a fine-grained analysis of the representational levels' students use to describe and explain Mendelian genetics.

- The presented analysis contributes to extending our comprehension of how high school students use representations and specify the differences between representational levels' trajectories in three class scenarios.

- Determining students' representational levels and trajectories contributes to the development of educational strategies that include external representations. This approach provides a first-hand account of the possible trajectories used by students, possibly leading to a better understanding of their learning processes and the use of representations in the classroom.

\section{Learning and Representations}

Research on representations has proven helpful in understanding students' conceptual difficulties while learning complex scientific topics (Pande \& Chandrasekharan, 2017; Prain \& Tytler, 2012). The representational analysis is focused on both the construction of students' representations of processes and models in their mind (internal representations) and the use of external representations to foster learning, such as the used by the teacher and showed in textbooks to promote student's understanding, and expressed in several formats: verbal-textual, symbolic-mathematical or visual-graphic (Wu \& Puntambekar, 2012).

For the students' models of genetics, research has focused on three genetic models: Mendelian (referred to the mechanism of inheritance and expression of dominant and recessive characteristics), meiotic (which considers the formation of gametes as a source of genetic variability), and molecular (which focuses on the way gene expression occurs) (Bresler, Golan, \& Shea, 2011; Gericke \& Wahlberg, 2013; Stewart, Cartier, \& Passmore, 2005). Their results show that students' comprehension of these models is consistent with the previously described learning difficulties. However, very little knowledge exists concerning the changes and refinement process students follow in their representations and learning process.

External representations are now well known to promote the comprehension of scientific concepts. For example, Schonborn and Bogeholz (2013) showed that multiple external representations help students transition between different scales of biological processes, and Rotbain, Stavy, and Marbach-Ad (2008) demonstrated that representations improved students' learning about the process of gene translation to proteins.

Although students have the skills to build and understand these external representations routinely employed by teachers, they must develop different levels of representational competencies (diSessa, 2004; Tsui \& Tragust, 2013) to interpret and elaborate on more comprehensive representations. Representational competencies should involve the ability to comprehend, generate, and use different forms of representations (e.g., photographs, formulas, or verbal descriptions) in a specific situation or problem in an interconnected way and then communicate their understanding of the topic (Scheid et al., 2018).

Improving representational competencies is not an easy task. Students must use cognitive and representational resources to learn the concepts that underlie representations and recognise, interpret, and recreate the various ways of representing these concepts and principles. This kind of learning requires students to be capable of switching back and forth between various representational modes (verbal, written, and mathematical) and levels (language, models and theories) and integrating them to build their representations to understand and explain various phenomena.

\section{STATEMENT OF THE PROBLEM}

The role of internal and external representations has been discussed from various perspectives. Cognitive process analysis focuses on the elements that explain students' conceptual progress and the meaning of the characteristics of the representations used in the classroom and the skills students must develop to create and interpret these representations. The conceptual and educational aspects both generally relate to representational issues and, in particular, the need to identify the processes that require refinement in students. This refinement process does not simply aim to achieve greater detail or precision in representations; instead, it seeks to increase students' abilities to relate and integrate different sets of knowledge into their representations because they correlate with their comprehension of concepts and processes.

Although there are different ways to classify representations by levels and formats-for example, according to their function (enactive, iconic and symbolic; Bruner, 1990) or their dimensional format (3D gestures and objects, 2D virtual, photographs, diagrams and 1D symbolic; Gilbert, 2008)-usually these classifications do not provide the competencies students need to develop. Kozma and Russell's proposal (2005, p. 133) establishes a classification according to students' cognitive demand that involves the distinction between 
five levels of representation and the competencies needed, ranging from representations of basic actions through pictorial and gestural resources to those expressed through models and theories. The five levels are: 1 ) depiction; 2) early symbolic; 3 ) syntactic of formal languages; 4) semantic of formal languages; and 5) reflective, rhetorical use of models and theories. Traversing through these levels initially entails a representational process of refinement, requiring students to integrate knowledge through complex relationships that enable modelling or have an explanatory theoretical framework articulated, consistent, and adaptable to different situations, grade and school context.

Based on the hypothesis that alternating between representational levels implies different processes of representational comprehension, refinement gives rise to various questions: Which path or trajectory across levels enables students to reach adequate refinement and comprehension of the topics perceived as complex (as is the case with genetics)? To what extent does transitioning between levels of representation mean that students can establish relationships between the content knowledge of different descriptive levels, including shifting from the macroscopic to the microscopic level? Does a class that uses a wider variety of external representations favour representational trajectories that lead to a better level of comprehension, in contrast to a traditional class?

An analysis of the various representational levels built by students to describe and explain phenomena will illuminate their comprehension and use of representations and provide elements to support the refinement of their representations, and identify the trajectories across levels in different class scenarios.

\section{Objectives}

In order to respond to the questions above, the main objectives of this research are to:

- To determine the relationship between the various levels of representation, refinement, and integration processes among high school students learning Mendelian genetics; and

- To specify the differences between the trajectories of representational levels reached by students.

Three strategies using different types and quantities of external representations were developed and applied in the classroom to achieve those objectives. An assessment instrument was used to collect data, and classification of representational levels was developed for the analysis. Differences between teaching processes were determined using ANOVA. The following section describes the analytical process and methodology.

\section{METHOD}

\section{Research Design}

This study involved a mixed-method research approach. It is a descriptive study with qualitative and quantitative data and statistical analysis. As mentioned previously, three different didactic strategies were designed in the type and number of external representations that were used with three different school groups. The headteacher of each school group carried out the teaching activities for four weeks, 4 hours each week. Students of each school groups took an assessment instrument two weeks after completing their class activities to avoid remembering drawings and images in short term memory.

\section{Participants}

The study was conducted with a non-probabilistic sample of 186 high school students (15 to 17 years old) at the High School System administrated by the National Autonomous University of Mexico (Universidad Nacional Autónoma de México [UNAM]) who were studying Biology 5 . The study was carried out with three school groups that the school administration already determined: G1 (60 students; 45 women, 15 men), G2 (60 students; 46 women, 14 men) and G3 (66 students; 50 women, 16 men). Each teacher applied only one of the three different didactic strategies to their school group (strategies that differ in types and quantities of external representations). The three teachers were biologists with 20-25 years of teaching experience, and all participated voluntarily. The school groups were similar in terms of socioeconomic level, academic trajectory, availability of digital technology resources inside the school, and interest in future studies in the chemistry-biology field. Genetics is taught in-depth for the first time in Biology 5; previous middle school courses addressed this topic in less detail.

\section{Topics for Analysis}

High school education programs comprehensively address genetics. Indeed, there are different good ways of organising the themes of genetics for teaching (GolanDuncan et al., 2016). The school program is compulsory for high school at UNAM. This program (ENP, 2018) covers a variety of topics and organisation levels of genetic processes: (A) Cellular Specialization refers to the genetic information present across different cell types within an organism and how it is expressed for a given trait; (B) Law of Independent Assortment describes the independent expression of inherited traits through the description of inherited blood types and other traits; (C) Traits and Differences between Haploid (sexual) and Diploid (somatic) Cells refers to the genetic information contained in these cells, as well as their origin and functions; (D) Mechanisms of Inheritance, 
Table 1. Frequencies for types of representations by group

\begin{tabular}{lccc}
\hline Type of representational resources & G1 & G2 & G3 \\
\hline Verbal textual & 20 & 17 & 24 \\
Symbolic mathematical & 6 & 9 & 21 \\
Visual graphical & 17 & 24 & 40 \\
Actional operational & 1 & 1 & 8
\end{tabular}

Note: Some examples of the types of representations in the activities are: Verbal textual (to read a text that describes the organization of genetic material), symbolic mathematical (to solve some Punnett square exercises, visual graphical (to observe a cell cycle image), and actional operational (to perform an experimental activity of mitosis and some observations under the microscope).

including dominance-recessiveness and multiple alleles, explains the probabilities of inheritance and the expression of a particular trait based on parents' genotype and phenotype; and (E) Genetic Variability analyses the recombination processes involved in the inheritance, including meiosis and the crossover of homologous chromosomes.

\section{Teaching Activities}

The research team designed the three strategies used in the classroom based on a student-centred perspective on learning construction (Gallegos-Cázares, 2015). Each strategy included six activities, and each activity addresses a specific conceptual sequence (levels of organisation of genetic material, cellular specialisation, law of independent assortment, traits and the differences between haploid and diploid cells, mechanisms of inheritance, and genetic variability). Each activity consists of five phases: 1) approximation to the context (where the topic and its importance is discussed); 2) development (where various activities are conducted to address specific concepts; 3) analysis of results; 4) construction of explanations (students present and discuss their explanations); and 5) conclusions. For each activity, teachers identify the concepts and processes to be addressed and adapt the didactic suggestions to use the teaching resources proposed. The conceptual content and sequence of the activities and teaching hours were the same for the three groups; however, the number and type of representational resources in each strategy differed according to each teacher's style. The representations included in the strategies follow $\mathrm{Wu}$ and Puntambekar's (2012) classification: verbal-textual (oral exposition, written text), symbolic-mathematical (equations, formulas), visual-graphical (animations, simulations, conceptual maps, diagrams, graphs tables), and actional-operational (demonstrations, experiments, gestures, manipulations of physical models). In the activities, a balance of type of representations was considered. Table 1 shows the frequencies for the type of representation by each school group.

Table 2 presents an example of the differences in the activities (levels of organisation of the genetic material), indicating resources and teaching performance. All the activities share a similar design.

\section{Assessment Instrument}

A 13-item assessment instrument focused on the five topics addressed by teachers was used to identify student representations. The instrument was designed to specify students' ideas and representations regarding the phenomenon. As we mentioned previously, the representational approach is effective for teaching complex issues such as the one addressed in this work. Therefore, it is necessary to use instruments that, in line with this approach, allow identifying the set of elements that make up the student representations. The instrument's questions are based on describing a problematic situation and oriented to the construction of explanations and how these constructions relate to participants' experiences. (An example is provided in the next section.) In addition to considering the representational approach that supports it, the questions enable participants to use written responses, drawings, symbols, and diagrams to demonstrate the comprehensiveness and refinement of their representations.

The instrument was examined under different validation criteria (clarity of the questions, obtaining expected answers, relevance, the intelligibility of items, completeness, and equivalent structure) with a sample of 60 students (from the same population but different from the study sample) and three biology teachers (different from teachers of this study). Statistical reliability and item characterisation were examined with a sample of 387 students, also from the same population but different from the present study. The data used for the statistical tests were obtained from a rubric to guarantee that values were assigned consistently. The rubric follows Wilson's (2005) proposal. The instrument's reliability, Cronbach's alpha coefficient (0.88), and its characterisation with the Rasch partial credit model evidence an instrument with a range of difficulty between the items from -0.84 to 0.42 ( \pm 1 logit). These results indicate a reliable instrument that characterises various types of external representations of students. For a detailed description of the instrument's validation, see Flores-Camacho et al. (2017).

From the questions, it is possible to identify information on more than one topic. The relationship between the topic and questions is: Topic $\mathrm{A}$, items 5 and 7d; Topic B, items 2, 3, and 4; Topic C, items 3, 4, and 6; Topic D, items 7 and 8; and Topic E, items 1 and 12. For the present study, item 9 was excluded because the answers obtained focused on the types of mutations and did not provide elements for identifying their inheritance patterns and genetic. 
Table 2. Example of the resources and working methodology

Objective: To recognize main concepts of genetics and levels of organization of genetic material by identifying student's ideas, as well as the way in which different involved structures are represented by them.

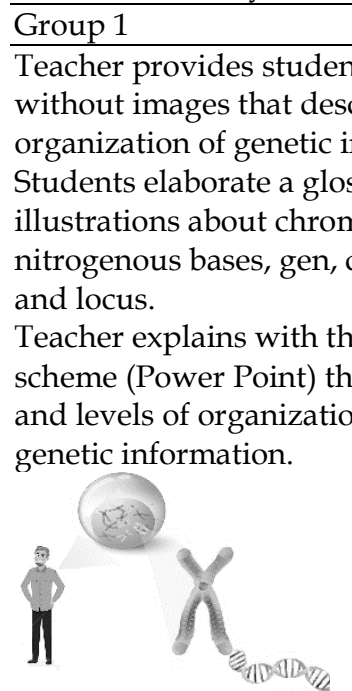

Each student elaborates a conceptual map to describe hierarchies and relationships of the glossary concepts.

\section{Group 2}

Teacher provides students with a text with images that describe the organization of genetic information. Students elaborate a glossary about chromatin, ADN, nitrogenous bases, gen, chromosome and locus.

The teacher explains with the aid of a scheme (PP) the concepts and levels of organization of the genetic information.

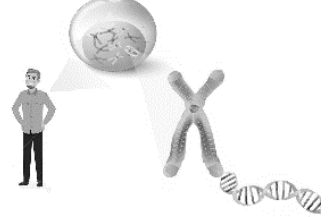

Each student organizes printed figures to show the organization hierarchies of genetic information.

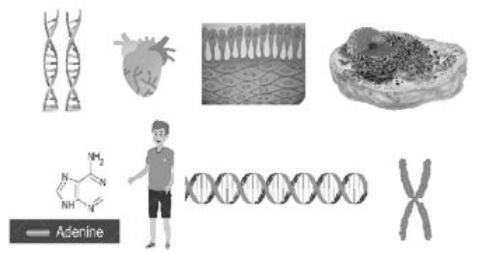

Each student elaborates an illustrated conceptual map to describe hierarchies and relationships of the concepts of the glossary.

\section{Group 3}

Teacher provides students with a text with images that describe the organization of genetic information. Students elaborate a glossary with illustrations about chromatin, ADN, nitrogenous bases, gen, chromosome and locus.

Teacher explains with the aid of a scheme and an analogy (PP) the concepts and levels of organization of the genetic information.
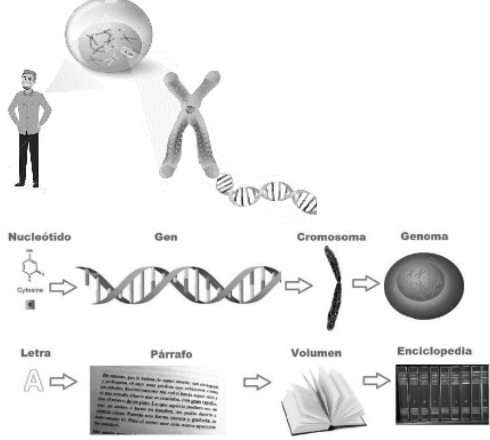

In teams' students use a simulator about the levels of genetic organization.

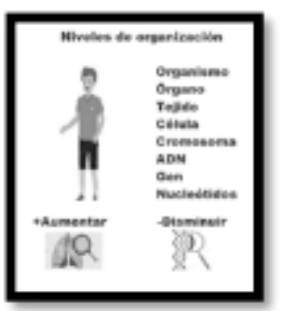

Each student works with a presentation (PP) to organize hierarchically the levels of genetic information

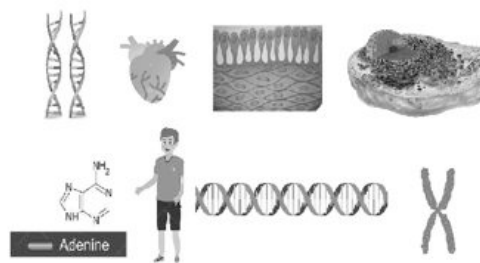

Each student elaborates an illustrated conceptual map to describe hierarchies and relationships of the concepts of the glossary.

\section{LEVELS OF REPRESENTATION: ANALYSIS FRAMEWORK}

To characterise the student's responses, we proposed four levels inspired by Kozma and Russell's (2005) proposal previously described, where the levels of representations range from the depiction of objects and actions to the reflective use of models and/or theories. In Mendelian genetics, the levels should be able to progressively describe the genetic components and structures, function, mechanisms and processes, and models of the genetic material.

The levels here proposed are novel and comprise from descriptions on the level of perceptible hereditary phenomena, which are visible to students, to explanations of mechanisms of inheritance. These levels were used to analyse students' answers (written texts and drawings, and diagrams) and classify them accordingly. The representational proposed levels are:

Level 1 Representations with similarity to the physical aspects of the phenomenon represented (through words or graphics) that refer to an entity or element by appealing only to macroscopic characteristics.

Level 2 Representations of different genetic elements that neither involve relationships with other representations nor contribute to creating explanations; representations are created using figures or symbols. 
Level 3 Relationships are established between representational elements to construct explanations; processes or sequences of processes can be written with drawings and symbols. New representations are built from previous representations, denoting causal reasoning.

Level 4 Representational systems that include models and theories are developed to build explanations. Chains of explanatory relationships are written in symbolic or graphic form from the inferred genetic theory.

The qualification of the assessment instrument consisted of assigning representation levels to students' responses to each item. A rubric that jointly considered the texts, graphs and drawings of student's responses was designed and applied by two biologists of the research team to achieve this. The inter-judge reliability was over 90\%, and differences were solved by consensus.

The values assigned to the items range from 0 to 4 . ANOVA was applied to identify the differences between the school groups (G1, G2, and G3) based on the didactic strategy. Because each theme implies a different conceptual and representational demand, it is relevant to compare the school group differences by topic.

Table 3 shows how the representational levels were assigned to student answers. The example presented below corresponds to topic D, Mechanisms of Inheritance, and shows students' answers to section A in question 7 (Figure 1).

Table 3. Representational levels to explain the mechanisms of inheritance

\begin{tabular}{|c|c|c|c|c|}
\hline Level & Description & Students' answers & & \\
\hline $\begin{array}{l}1 \\
\text { (Representations } \\
\text { with similarity to } \\
\text { the physical } \\
\text { aspects) }\end{array}$ & $\begin{array}{l}\text { Answers focused on } \\
\text { perceptible characteristics. } \\
\text { They neither explain the way } \\
\text { in which genetic information } \\
\text { is in sexual cells and how it is } \\
\text { passed to a new individual, } \\
\text { nor do they express } \\
\text { inheritance mechanisms. }\end{array}$ & a) Elóvulo: & b) El espermatozoide: & c) Las céluluas del bébe: \\
\hline
\end{tabular}

(Representations perceptible characteristics. with similarity to They neither explain the way the physical in which genetic information aspects) is in sexual cells and how it is passed to a new individual, nor do they express inheritance mechanisms.

$2 \quad$ They perceive that trait (Representations expressions are related to of genetic genetic information and are elements represented through without relating chromosomes, genes, alleles, them) or DNA.

\section{3} (Relationships between representational elements)
More than one item is used to represent genetic information in gametes (genes,

chromosomes, DNA, and/or alleles) and relates them with trait expression.
The student connects what is in the parents' cells (egg, sperm) with the trait that each of them expresses. In the baby's cells, the student includes both traits and not use symbols.

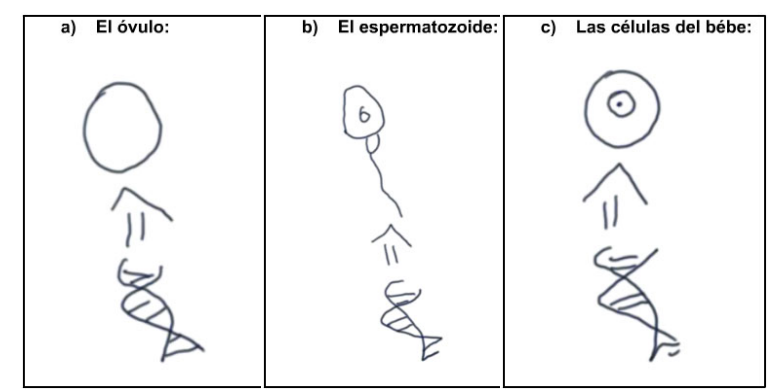

The student indicates DNA in the egg, the sperm and baby's cells, represented as a double string. The student doesn't explain more about the trait asked about.

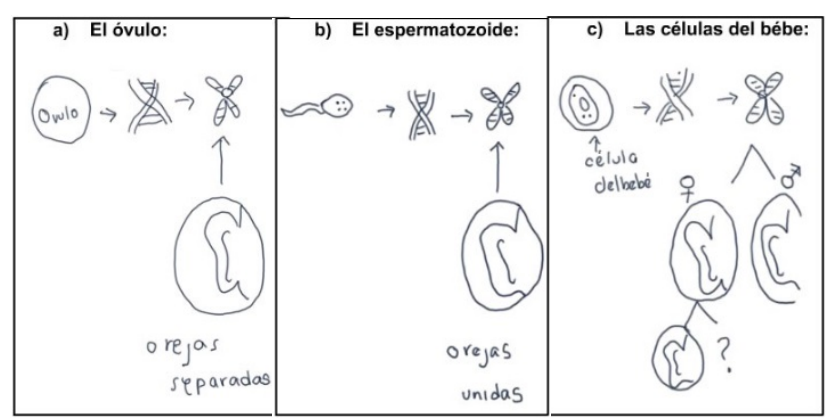

The student relates cell DNA, presented as a chromosome, with information about the inherited trait. On the chromosome marks the information that the student considers corresponds to the maternal and paternal phenotype. The student recognizes the mother's information inherited in the baby's cells. 
Table 3 (continued). Representational levels to explain the mechanisms of inheritance

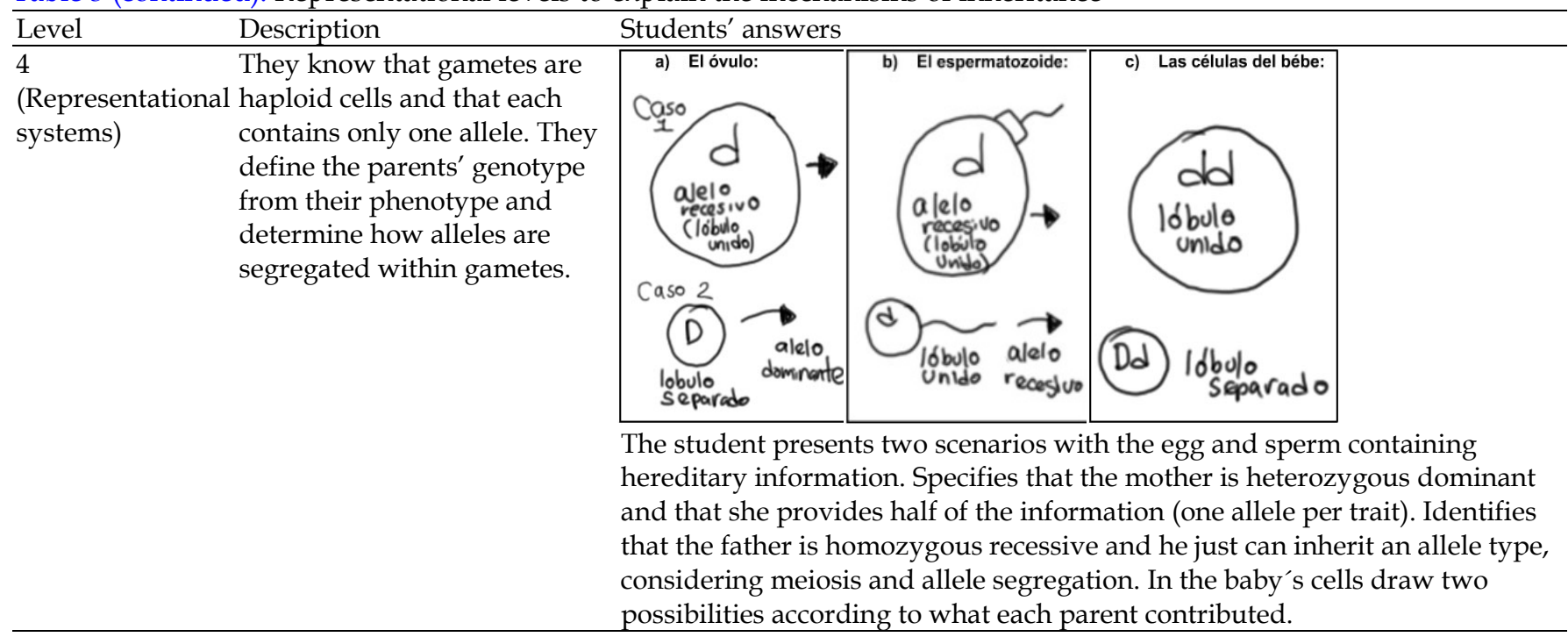

\section{Look at the following images to identify earlobe attachment in Alicia and Mauricio. They}

have heard that detached earlobes constitute a dominant trait, but Mauricio is sure that a

baby could be born with attached earlobes because Alicia's mother also shares this trait

(her picture is also included).

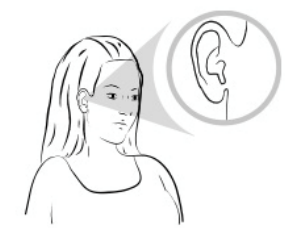

Alicia, detached earlobes

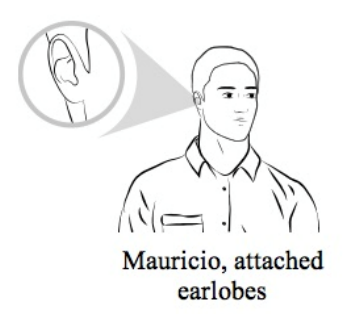

earlobes

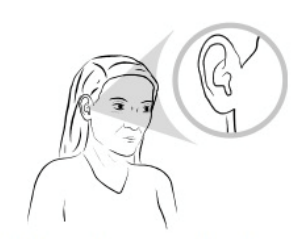

Alicia's mother, attached earlobes

\section{To help them figure it out, draw the way in which you think hereditary information for}

attached or detached earlobes appears in a) the egg

Figure 1. Question 7 of the assessment instrument

\section{RESULTS}

\section{Levels}

The analysis of students' answers showed that they employed different representational levels; thus, they appeal to different representational levels to answer the questions by building their explanations for each topic. Level 2 was the most frequent (505 times), indicating that most students build representations without relating them to other representations or integrating figures or symbols in their arguments, followed by level 3 (200 times), where students can establish relationships between representations. As expected, only a few students reached level 4 (32 times). This result is consistent with those by Lewis y Wood-Robinson (2000), which indicate that students between 14 and 16 have confusion and difficulty in relating the processes of inheritance, meiosis and expression of genetic information.

The results showed that the differences were significant for all of the topics across the three groups (see Table 4). The highest F-value (54.417, $p<0.05$ ) indicates that the most prominent differences among the school groups concerned topic A on cellular specialisation, which is a complex topic because students must link DNA transcription and mRNA translation for protein synthesis in cell specialisation. The lowest Fvalue $(19.224, p<0.05)$ was found for topic $C$, diploid and haploid cells. 
Table 4. Variance analysis for differences between groups by topic

\begin{tabular}{|c|c|c|c|c|c|c|}
\hline Topic & Group & $\mathrm{N}$ & Mean & SD & $F$ & Sig. \\
\hline \multirow[t]{3}{*}{$\mathrm{A}$} & G1 & 60 & 1.28 & .555 & \multirow{3}{*}{54.417} & \multirow{3}{*}{.000} \\
\hline & G2 & 60 & 1.25 & .600 & & \\
\hline & G3 & 60 & 2.25 & .714 & & \\
\hline \multirow[t]{3}{*}{ B } & G1 & 60 & 2.15 & .659 & \multirow{3}{*}{42.472} & \multirow{3}{*}{.000} \\
\hline & G2 & 60 & 2.07 & .607 & & \\
\hline & G3 & 60 & 3.00 & .632 & & \\
\hline \multirow[t]{3}{*}{$\bar{C}$} & G1 & 60 & 1.93 & .773 & \multirow{3}{*}{19.224} & \multirow{3}{*}{.000} \\
\hline & G2 & 60 & 1.80 & .684 & & \\
\hline & G3 & 60 & 2.50 & .614 & & \\
\hline \multirow[t]{3}{*}{$\bar{D}$} & G1 & 60 & 1.87 & .566 & \multirow{3}{*}{34.823} & \multirow{3}{*}{.000} \\
\hline & G2 & 60 & 2.02 & .431 & & \\
\hline & G3 & 60 & 2.67 & .687 & & \\
\hline \multirow[t]{3}{*}{$\bar{E}$} & G1 & 60 & 1.75 & .437 & \multirow{3}{*}{22.754} & \multirow{3}{*}{.000} \\
\hline & G2 & 60 & 1.83 & .526 & & \\
\hline & G3 & 60 & 2.36 & .671 & & \\
\hline
\end{tabular}

Table 5. Tukey's homogeneous groups for each topic

\begin{tabular}{|c|c|c|c|c|c|}
\hline \multirow[b]{2}{*}{ Topic } & \multicolumn{5}{|c|}{ Strategies } \\
\hline & Subset for alpha $=0.05$ & G1 & G2 & G3 & Sig. \\
\hline A & 1 & 1.29 & 1.26 & - & 0.981 \\
\hline (Specialization) & 2 & & -- & 2.3 & 1 \\
\hline B & 1 & 2.21 & 2.16 & - & 0.921 \\
\hline (Independent assortment) & 2 & - & - & 3.13 & 1 \\
\hline $\mathrm{C}$ & 1 & 1.98 & 1.85 & - & 0.552 \\
\hline (Haploid/diploid) & 2 & - & - & 2.57 & 1 \\
\hline $\mathrm{D}$ & 1 & 1.97 & 2.08 & - & 0.329 \\
\hline (Mechanisms) & 2 & - & - & 2.78 & 1 \\
\hline $\mathrm{E}$ & 1 & 1.79 & 1.86 & - & 0.743 \\
\hline (Variability) & 2 & - & - & 2.39 & 1 \\
\hline
\end{tabular}

To identify the behaviour of each school group by topic and define whether subgroups are present in respect to the means obtained, a Tukey test for homogeneous groups was applied (Table 5). The results showed that two subsets were obtained in all topics: one including G1 and G2 and another including G3. The maximum significance value between G1 and G2 (0.98) appeared in topic A (Cellular Specialization), and the minimum value (0.32) appeared in topic $\mathrm{D}$ (Mechanisms of Inheritance). These data hint at the favourable effect of using multiple representations. Although most students did not reach levels 3 and 4, the effect was favourable to students who belong to G3 (the group exposed to a greater diversity of representations). This result indicates a positive answer towards the research question oriented towards the implications of the variety of external representations. These aspects coincide with Kozma (2003), who highlights that experts in a subject use characteristic of various representations individually and together to understand processes, so they use them flexibly and fluidly.

Students appealed to various levels of representation. Through these levels, their responses' learning pathways or trajectories can be traced back to explain the elements and relationships used to build their representations, providing evidence of their representational comprehension and refinement.

\section{Trajectories}

In order to determine student's trajectories, the highest level of description or explanation attained by each student in each topic was considered. For example, if a student used levels 1 and 2 in his or her answers for topic A (Cellular Specialization), then level 2 was considered the maximum level. The same procedure was followed for each topic. In this way, each participant obtained a $\mathrm{T}$ trajectory, i.e., $\mathrm{T}$ (student 178$)=(\mathrm{A}: 1$; B:3; C:1; D:3; E:2). The letter indicates the topic and the number the representational level reached. The trajectories of all students enabled us to identify the set of trajectories used to answer the instrument.

We identified five trajectories: Trajectory I includes representational levels 1 and 2; Trajectory II uses levels 1, 2, and 3; Trajectory III uses levels 2 and 3; Trajectory IV includes levels 2, 3 and 4 , and Trajectory $\mathrm{V}$ is composed of levels 3 and 4. Table 6 shows the percentages of students showing each trajectory.

The percentages by trajectory show that most students (48\%) were in Trajectory I. Their responses rely on descriptions of observable traits, and they can build primary symbolic representations only, as exemplified by the fact that they refer to genotypes using symbols (letters) but fail to establish relationships with other representations and concepts. More significantly, few students in level 1 reach Trajectory II but non reach 
Table 6. Trajectories for students' levels of representation

\begin{tabular}{|c|c|c|c|c|c|c|c|c|}
\hline \multirow[t]{2}{*}{ Trajectories } & \multicolumn{4}{|c|}{ Levels Included } & \multicolumn{4}{|c|}{ Percentage by Group } \\
\hline & 1 & 2 & 3 & 4 & $\begin{array}{c}\mathrm{G} 1 \\
(\mathrm{n}=60)\end{array}$ & $\begin{array}{c}\mathrm{G} 2 \\
(\mathrm{n}=60)\end{array}$ & $\begin{array}{c}\mathrm{G} 3 \\
(\mathrm{n}=60)\end{array}$ & $\begin{array}{c}\text { Total } \\
(\mathrm{n}=180)\end{array}$ \\
\hline $\mathrm{I}$ & $X$ & $X$ & & & $67 \%$ & $75 \%$ & $8 \%$ & $48 \%$ \\
\hline II & $X$ & $x$ & $X$ & & $20 \%$ & $13 \%$ & $12 \%$ & $15 \%$ \\
\hline III & & $x$ & $x$ & & $10 \%$ & $10 \%$ & $52 \%$ & $25 \%$ \\
\hline IV & & $x$ & $x$ & $X$ & $3 \%$ & $2 \%$ & $22 \%$ & $10 \%$ \\
\hline V & & & $x$ & $x$ & $0 \%$ & $0 \%$ & $6 \%$ & $2 \%$ \\
\hline
\end{tabular}

trajectories IV and V. Similarly, most of the students who began at level 2 were in Trajectory III, but few could transition from level 2 to level 4 (Trajectory IV). Only $2 \%$ of students were in Trajectory $\mathrm{V}$, integrating processes or using models to supplement their explanations. This relation between initial level and trajectory (detailed in the next section) has implications for teaching processes and how teachers consider representations.

\section{Differences among the school groups by student trajectory}

A comparison of the trajectories reveals that higher levels of representational competence are related to the type of strategy used in the classroom (see Table 5). Although most of the participants used Trajectory I $(48 \%)$, their percentages were highest in G1 and G2 $(67 \%$ and $75 \%$, respectively). Conversely, students in G3 predominantly used Trajectories III (52\%) and IV (22\%), and they included the only students who employed Trajectory V (6\%). This difference shows that students in G3 built more complete explanations that incorporate and relate representations. This means that the teaching strategy used with G3 was better in enhancing student's genetic understanding, whereas G1 and G2 employed less detailed and poorly integrated representations.

\section{ANALYSIS}

The present analysis is focused on how higher levels of representation and trajectory result in a better approximation to the proper comprehension that involves valid relationships between concepts and processes and not on memorised correct answers. The following section describes each identified trajectory's conceptual and representational characteristics.

\section{Trajectories, Refinement, and Comprehension}

\section{Trajectory I: Levels 1 and 2}

Students in Trajectory I used representational levels 1 and 2 in their answers. Their representations were characterised by descriptions that do not relate to other representations, nor do they generate explanations. Students only paraphrased aspects mentioned in the assessment instrument. Their drawings referred to perceptible aspects of what they claimed to represent (phenotypes or basic cell structures) without including processes that demonstrate what they understand about the topic. For example, a typical response to the question 'Why are some traits inherited from the father and others from the mother?' (Question 12; topic E, Genetic Variability) is: 'Because there will always be dominant genes, either in the phenotype or in the genotype. This answer shows that the student recognises the existence of dominant genes (alleles) and considers that they are responsible for the expression of a character. However, he exhibits his confusion by manifesting independence between phenotype and genotype. In short, students in this trajectory can identify some elements of the structure of the genetic information and enunciate some processes but cannot explain or use them to deepen their answers.

\section{Trajectory II: Levels 1, 2, and 3}

Few students in this trajectory reach level $3(15 \%)$. They incorporate the description of specific processes in written and graphic form. For example, in question 12, 'Why, despite having the same parents, are siblings different?' (Topic E), one student answered, 'Because in the nucleus of cells is the genetic material and characterises us as different and unique individuals.' This answer, although correct, does not provide elements to identify comprehension of the process, and therefore is classified as level 1. In question 3, topic C, 'Describe what kind of genetic information is found in the gamete and how it is passed on to offspring', the same student explained, 'The sperm is haploid because it carried out meiosis. It needs the egg, which is also haploid so that in fertilisation, both unite their chromosomes and return to diploidy, to form a baby.' This answer shows that she understands that a cell-formation process ('meiosis') is responsible for inheritance and that these cells carry half of the parents' genetic information (she said '....in fertilisation both unite their chromosomes and return to diploidy'). This thinking process reveals that she is capable of passing or refining their representations until level 3. This trajectory indicates that the student's comprehension of hereditary processes allows her to describe mechanisms and processes, yet she cannot articulately connect them. One example of graphical representations used by a student in this trajectory for topic D is shown in Figure 2, corresponding to question 7 , which requests the student to indicate the genetic information that, according to the example in the question, is in: a) the egg, b) the sperm, and c) the baby's cells. 


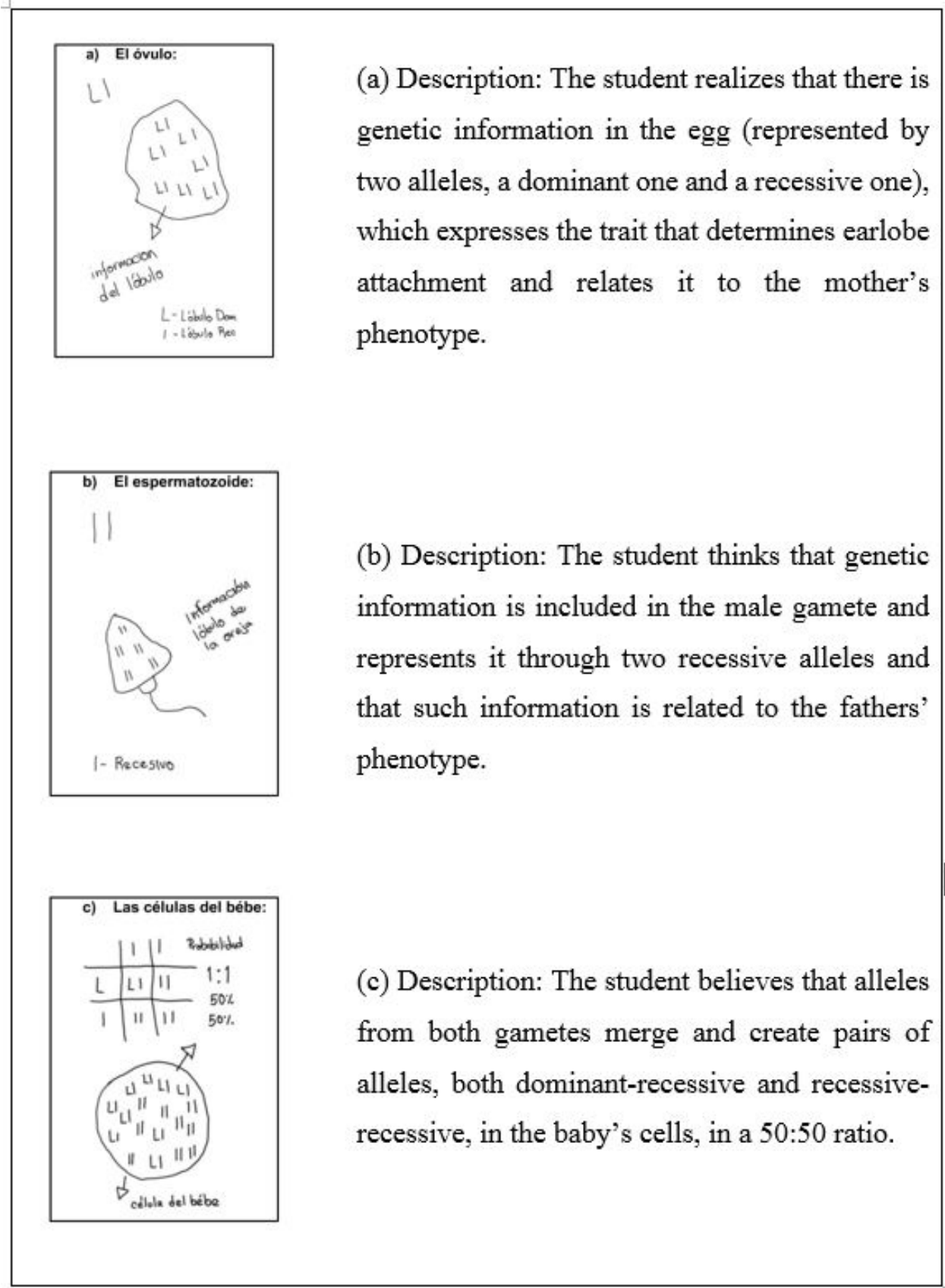

Figure 2. Examples of level 2. Graphical and symbolic representations (topic D)

\section{Trajectory III: Levels 2 and 3}

In this trajectory, students recognise characteristics and elements that constitute genetic processes and can establish relationships between some of these processes. However, they do not necessarily create or use models that demonstrate a broad comprehension of the foundations of genetics. For example, students who answer Question 12 (Topic E) (i.e., why biological siblings are different) describe the process of meiosis, incorporating different structures (chromosomes and genes) as in this example: 'During the stage of meiosis, specifically in prophase I, the cross-linking of chromosomes takes place. Each parent contributes one allele with different genes, and their cross results in a genetic exchange that will provide the baby with new and different characteristics.
Because of this, siblings are not much alike, even if they have the same parents.'

It is important to highlight that although the answer is located at level 3, where the student relates processes, the student's response still presents conceptual errors (such as considering that meiosis occurs in fertilisation or that alleles can have different genes). Similarly, when a graphic description (Question 3) is requested to indicate what kind of genetic information is found in the gamete and how it can be represented, the drawings created include the genetic information in the egg as chromosomes because they are involved in different processes regarding the formation of a new being. Figure 3 shows an example of a level 3 graphical representation (topic C). 


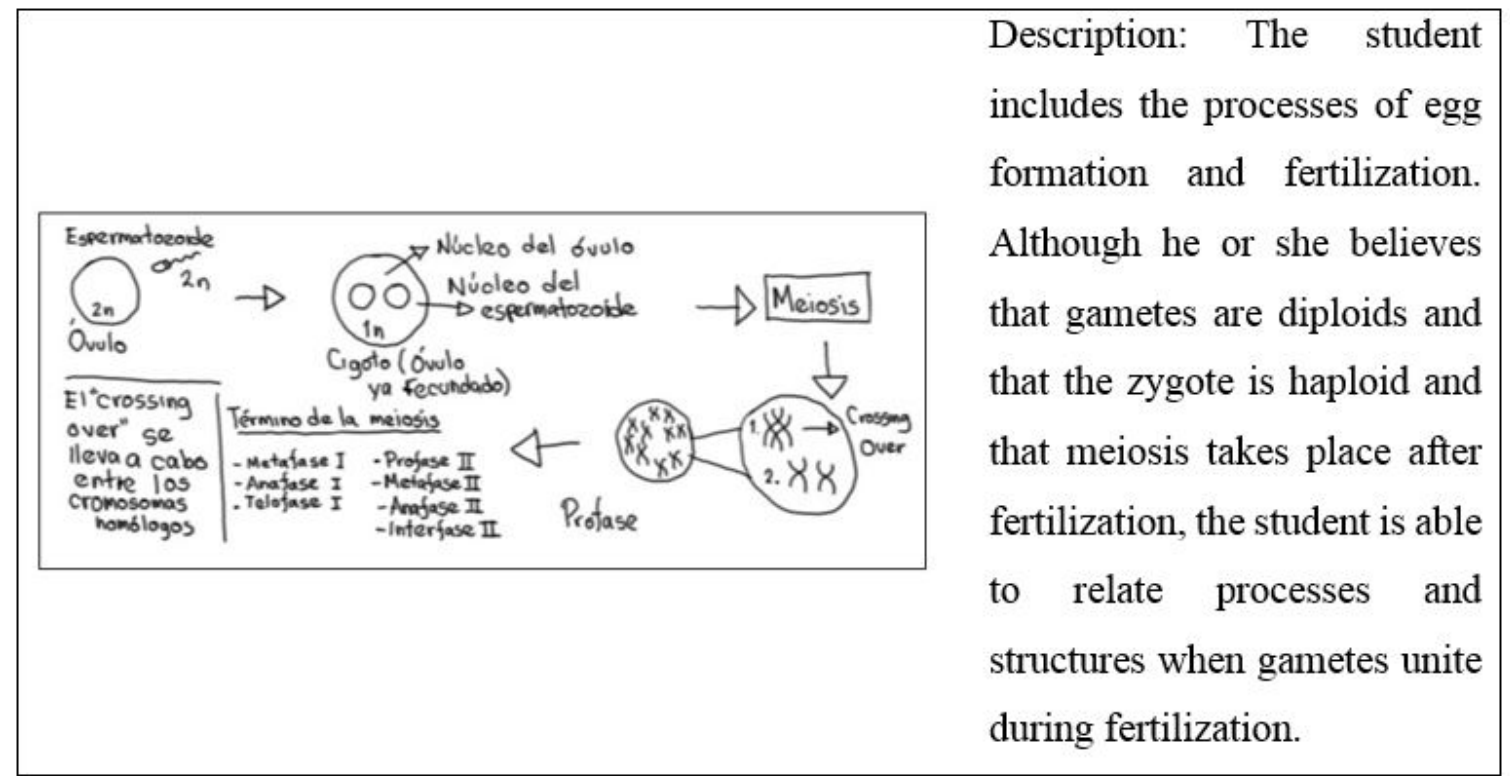

Figure 3. Example of a level 3. Graphical and symbolic representation (topic C)

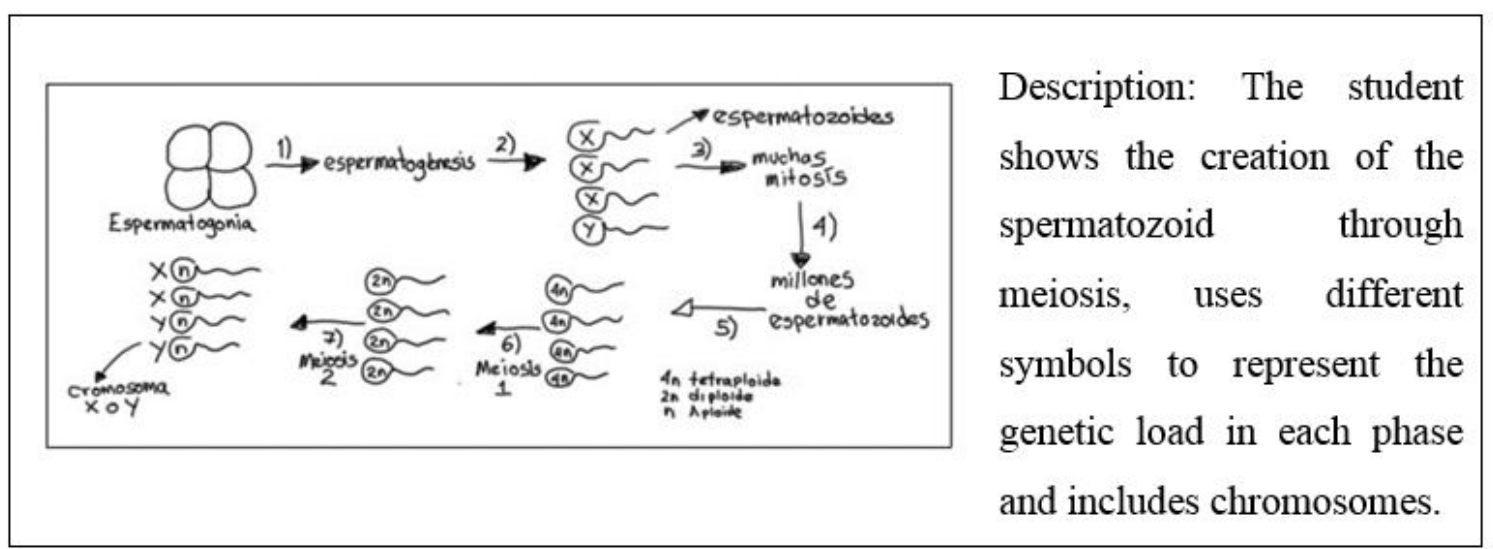

Figure 4. Example of a level 4. Graphical and symbolic representation (topic C)

\section{Trajectory IV: Levels 2, 3, and 4}

Students incorporate symbols and relationships between representations and between the processes described to generate more precise and more consistent explanations in the previous trajectory. For example, referring again to question 12 (i.e., why biological siblings are different), one student answered: 'At the genetic level, because of two processes: inter-chromatic crossing (random segregation from the father and mother) and the crossing over or cross-linking of chromosomes during metaphase I of meiosis, which results in genetic variability, a different phenotype in the new individual, and (at the population level) evolution... regarding epigenetics, depending on the cellular environment, individual habits, food, and others, the expression of the genotype may change; for example, a disease might appear in a family line that did not exist before.' This student mentions random segregation and epigenetics, which relate to evolution and phenotypic expression by incorporating chromosomes. This ability to represent processes and relationships is also present in the students' graphic representations (Figure 4) of the genetic information found in a gamete and how it can be represented. Students drew different structures and their referents at different organisational levels (chromosome and DNA) and justified cell haploid through meiosis in this representation. Students have developed some refinement by creating more detailed and structured representations of hereditary mechanisms in this trajectory.

\section{Trajectory V: Levels 3 and 4}

In Trajectory IV, students can establish and elaborate on relationships among the representations and incorporate processes and sequences of processes into written and drawn representations. In addition, they apply theoretical models to further their explanations of some topics. Only four students in G3 reached this trajectory ( $2 \%$ of the sample).

Figures 5a (Topic C) and 5b (Topic D) show two examples comparing two students' answers, one in Trajectory I and the other in Trajectory V. 


\begin{tabular}{|c|c|}
\hline \multicolumn{2}{|c|}{ Trajectory } \\
\hline I & $\mathbf{V}$ \\
\hline Topic C, Level 1. & Topic C, Level 4. \\
\hline areaved & 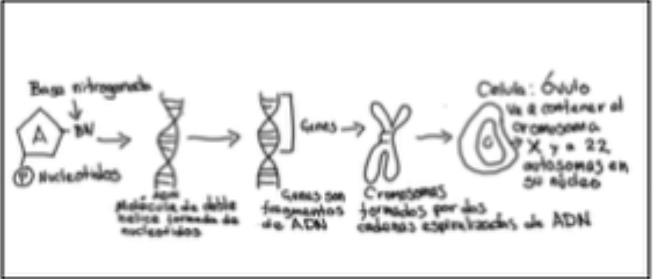 \\
\hline $\begin{array}{l}\text { Description: Student draws the nucleus in the } \\
\text { gametes but does not describe the genetic }\end{array}$ & $\begin{array}{l}\text { Description: The genetic information in the } \\
\text { gametes is haploid ( } 23 \text { chromosomes, only }\end{array}$ \\
\hline information. & $\begin{array}{l}\text { one is sexual). The genetic information is } \\
\text { represented according to the levels of } \\
\text { organization: nitrogenous bases, genes, } \\
\text { chromosomes, and DNA. }\end{array}$ \\
\hline
\end{tabular}

Figure 5. (a) Comparison of trajectories I and V for theme C

As seen, trajectories express the levels at which students represent various aspects of genetic processes. The higher the representational level reached in a specific trajectory, the greater the possibility of developing written responses and graphs that show their comprehension of the issues discussed in a coherent and integrated manner. Moreover, these trajectories show that student explanations require the use of various levels of representation. Trajectories IV and $\mathrm{V}$ indicate that processes of refinement and representational competence must be understood and explained. A brief analysis of both aspects is presented below.

\section{DISCUSSION}

\section{Topics, Levels, and Trajectories}

To what extent does transitioning between levels of representation mean that students can establish relationships between the content knowledge of different descriptive levels, including shifting from a macroscopic to a microscopic level? Topics in genetics must be expressed at different levels of representation based on the models that characterise them. Some require probabilistic models (e.g., Mendelian inheritance), whereas others require models that work at the molecular level. However, to reach all these models, students need to traverse the different levels of conceptual comprehension. Each topic refers to biological structures with different levels of organisation and functionality and processes with different levels of complexity. Thus, students interpret and understand topics using various levels of representation. In topics such as the law of independent assortment, student representations reach higher levels because they realise that genetic information is organised such that a gene is a part of the DNA sequence that is responsible for the expression of a trait.

Conversely, topics such as cellular specialisation, mechanisms of inheritance, or the difference between haploid and diploid cells are not clearly described using a model because students require understanding these topics better. Thus, students must proceed through these levels to develop representational competencies that will enable them to identify and use them in their pathways or trajectories. In other words, representations from both low (level 1 or level 2) and high (level 3 and level 4) levels are required to integrate the processes and structures involved in the comprehension of genetics.

Thus, with more demanding topics, teachers should encourage students to use the basic levels as springboards that enable the comprehension and use of higher and more sophisticated levels. 


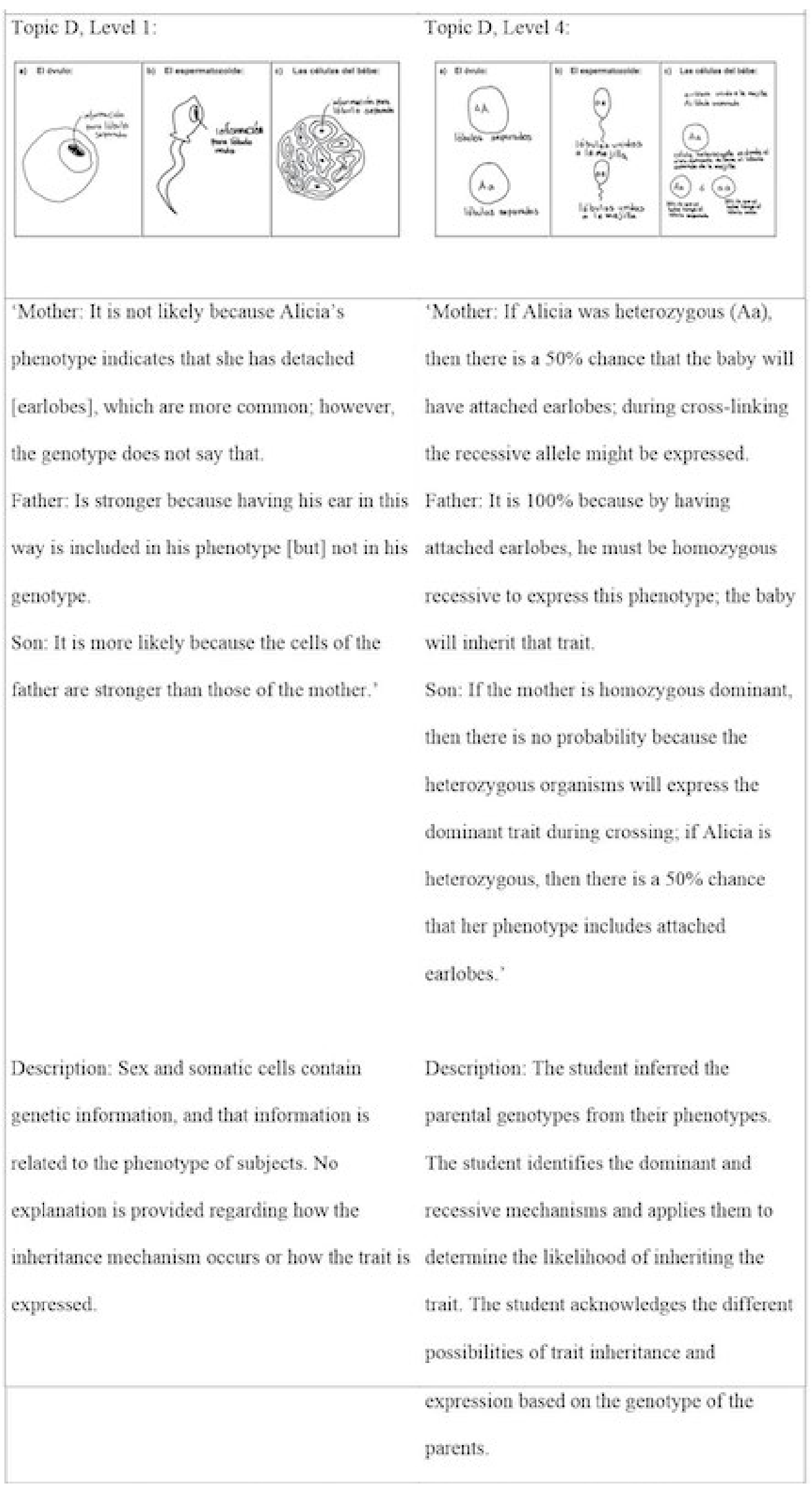

Figure 5 (continued). (b) Comparison of trajectories I and V for theme D 
Table 7. Representational trajectories, refinement, and the integration of the comprehension of genetics

\begin{tabular}{ll}
\hline Trajectories' transition & Representational refinement \\
\hline I, II $\rightarrow$ III & $\begin{array}{l}\text { Relate visible traits with structures and genetic processes. Causal explanations of some processes, not } \\
\text { necessarily related between them or totally coherent. }\end{array}$ \\
\hline III, IV $\rightarrow$ V & $\begin{array}{l}\text { Stablish relationships between macro and micro structures and processes. } \\
\text { Chains of causal explanations from macro expressions of traits to micro hereditary mechanisms. }\end{array}$ \\
\hline
\end{tabular}

\section{Trajectories, Refinement, and Comprehension}

One relevant aspect of these trajectories and a unique finding of our study is that they provide an accurate account of the refinement achieved by students in their representations. In addition to describing the elements or components of the different levels of organisation (verbally and graphically), this refinement involves being able to explain the mechanisms of relationship and function in hereditary processes. It also entails that students integrate hereditary processes while building and interpreting the models used by genetic theory. These aspects are observed by identifying the levels reached by students' explanations. Relating different representational levels requires various competencies in students that will help them interpret and connect these representations in a coordinated manner (diSessa, 2004; Tsui \& Tragust, 2013). In this way, it is expected that students who show Trajectories IV and V have a greater chance of achieving a competent level of comprehension and representation of the genetic issues according to the plan outlined in the high school syllabus. Students with Trajectories I and II are required to participate in some specific activities to foster the transit between representational levels, the development of these competencies is influenced by the availability of resources in the classroom and the ability of the teacher to articulate them to foster higher levels of student comprehension (Wu \& Puntambekar, 2012), along with helping students develop their representational competence. As Tsui and Treagust (2013) point out, this process implies modes of representation, levels of complexity, and the specific domain of knowledge.

From the relationship between trajectories, it is possible to recognise two significant transitions. These transitions answer the research question over which path or trajectory across levels enables students to reach an adequate refinement and comprehension. One transition is from Trajectory I or II towards Trajectory III. This transition implies that students' representations (written, drawn, schemas, graphs) show causal relations between terms, mechanisms, and processes that gradually abandon representations that only represent visible traits or that do not describe any process. For example, students who only represent visual aspects of the phenomenon and use terms or symbols that are common in the subject can subsequently describe processes to explain differences in cell types or the causes of variability and establish relationships between genotypes and phenotypes.
The other transition involves Trajectories III and IV towards Trajectory V. In this case; students start from a different level of comprehension because they can represent the processes in macro and microstructures along with related processes. They no longer appeal to perceptible aspects. An example is when students' representations show explanations of processes and mechanisms, such as cellular specialisation, the law of independent assortment, gametogenesis, inheritance mechanisms, and the origin of variability. Table 7 shows a synthesis of the refinement required to transit between Trajectories I and II to III, and II and IV to V.

As shown in Table 7, the refinement process implies the development of abilities needed to elaborate causal explanations chains, establish the relationship between macro and microstructures, and coherently integrate concepts. The proper comprehension of genetic concepts and processes is the main purpose of teaching science, but at a high school level (and even at a college level), this goal requires fostering the representational levels to achieve the proper conceptual comprehension.

How students are capable of representing processes is central to understanding learning processes. Through students' representations and process of refinement, it is possible to determine through a fine-grained analysis students' difficulties relating contexts, processes, and concepts in a coherent structure.

The complexities of genetics learning can be seen in the students' trajectories, mainly in the few students who can transit from the lower to the highest levels. It is also evident that incorporating resources that promote learning is insufficient (i.e., types of activities, external representations, and the use of activities and representations by teachers).

Determining representational levels and trajectories also contributes to the development of educational strategies that include external representations. The role of external representations is not limited to adding content or presenting information in different formats. These representations constitute epistemic entities that students must recreate and transform to modify their mental representations (Pande \& Chandrasekharan, 2017). As other authors have mentioned (Prain \& Tytler, 2012; Schonborn \& Bogeholz, 2013), differences in student learning do not depend on teachers incorporating external representations into their activities but on employing adequate strategies to help students understand the different representational formats and levels and also, working with students in the analysis of functions and limitations of 
representations when they are used as tools, assisting students' construction of their representations and improving their conceptual comprehension. As Ainsworth (2008) mentions, multiple external representations are powerful tools, but 'like all powerful tools, they need careful handling if learners are to use them successfully' (p. 191).

\section{CONCLUSIONS}

This study focused on the levels and trajectories of representations when learning Mendelian genetics and alerts us to foster an adequate comprehension of genetic processes, and teachers must ensure that most of the student's representations achieve level 3. To achieve level 3, the following suggested actions be carried out: 1) analyse what the representations mean (first as separate elements as in the case of gametes, chromosomes, and other structures, and then organised in sequences and causal relationships); 2) recognise the representational possibilities of different formats to represent different aspects of the process or phenomena; 3) characterise representations that help students move between a macro level and a molecular level, and 4) help students generate and explain their representations while keeping in mind that each representation has its limitations.

Studies that address the issue of representations in school have frequently been questioned about students' opportunities or previous experiences with online resources, arguing that their level of exposure can influence representational levels. There are two considerations on this issue: The first is that students belonging to the same socioeconomic level and residing in the same urban context (as in this case) have similar opportunities to access online resources. Students' interpretations of those resources are random, and therefore cannot explain the differences between groups of students (for example, between G1, G2, and G3). The second consideration is that understanding representations is not straightforward but requires some intentionality from teachers and an inferential use by students; therefore, online resources outside of educational settings can provide unexpected or at least unpredictable results. It would be interesting to know (in some particular cases) if a particular kind of resource has a strong influence and which are more significant. However, such a research project implies a specific research design beyond the scope of this work.

The process described to understand the processes of representational refinement and the role of the inclusion of multiple external representations in the classroom will require that certain methodological aspects and analysis criteria be honed. However, we believe that this approach provides a first-hand account of the possible trajectories used by students, possibly leading to a better understanding of their learning processes and the use of representations in the classroom.
Author contributions: All authors have sufficiently contributed to the study, and agreed with the results and conclusions.

Funding: This work was supported by the Consejo Nacional de Ciencia y Tecnología [CONACyT] under Grant Number 238712.

Acknowledgement: We thank Ph.D. Neil Bruce and Ms S. Rodrigo Flores for their review of the English text.

Declaration of interest: No conflict of interest is declared by authors.

\section{REFERENCES}

Ainsworth, S. (2008). The educational value of multiplerepresentations when learning complex scientific concepts. In J. K. Gilbert, M. Reiner, \& M. Nakhleh (Eds.), Visualisation: Theory and practice in science education (pp. 191-208). Springer. https:/ / doi.org/ 10.1007/978-1-4020-5267-5_9

Banet, E., \& Ayuso, E. (2000). Teaching genetics at secondary school: A strategy for teaching about the location of inheritance information. Science Education, 84(3), 313-351. https:/ / doi.org/10.1002/ (SICI)1098-237X(200005)84:3<313::AID-SCE2>3.0. $\mathrm{CO} ; 2-\mathrm{N}$

Bresler, F. H., Golan, D. R., \& Shea, N. (2011). Exploring middle school students' understanding of three conceptual models in genetics. International Journal of Science Education, 33(17), 2323-2349. https:/ / doi.org/10.1080/09500693.2010.536997

Bruner, S. J. (1990). Acts of meaning. Harvard University Press.

Chattopadhyay, A. (2005). Understanding of genetic information in higher secondary students in Northeast India and the implications for genetics education. Cell Biology Education, 4(1), 97-104. https:/ / doi.org/10.1187/cbe.04-06-0042

diSessa, A. A. (2004). Metarepresentation: Native competence and targets for instruction. Cognition and Instruction, 22(3), 293-331. https://doi.org/ 10.1207/s1532690xci2203_2

Duncan, R. G., \& Reiser, B. J. (2007). Reasoning across ontologically distinct levels: Students' understanding of molecular genetics. Journal of Research in Science Teaching, 44(7), 938-959. https:/ / doi.org/10.1002/tea.20186

Duncan, R., Castro-Faix, M., \& Choi, J. (2016). Informing a learning progression in genetics: Which should be taught first, Mendelian inheritance or the central dogma of molecular biology? International Journal of Science and Mathematics Education, 14(3), 445-472. https:/ / doi.org/10.1007/s10763-014-9568-3

Escuela Nacional Preparatoria. (2018). Plan de estudios [Curriculum]. Universidad Nacional Autónoma de México: México. http://dgenp.unam.mx/planesde estudio/quinto-2017.html

Flores-Camacho, F., García-Rivera, B., Báez-Islas, A., \& Gallegos-Cázares, L. (2017). Diseño y validación de un instrumento para analizar las representaciones 
externas de estudiantes de bachillerato sobre genética [Design and validation of a questionnaire to analyse high school student's external representations about genetic]. Revista Iberoamericana de Evaluación Educativa, 10(2), 151169. https:// doi.org/10.15366/riee2017.10.2.008

Gallegos-Cázares, L. (2015). Una propuesta didáctica para el trabajo en el laboratorio [A didactic proposal for work in the laboratory]. In F. FloresCamacho (Ed.), Las tecnologías digitales en la enseñanza experimental de la ciencia. Fundamentos cognitivos y procesos (pp. 81-120). Grañén Porrúa.

Gericke, N. M., \& Hagberg, M. (2007). Definition of historical models of gene function and their relation to students' understanding of genetics. Science Education, 16(7-8), 849-881. https://doi.org/ $10.1007 / \mathrm{s} 11191-006-9064-4$

Gericke, N., \& Wahlberg, S. (2013). Clusters of concepts in molecular genetics: A study of Swedish upper secondary science students understanding. Journal of Biological Education, 47(2), 73-83. https:/ / doi.org/ 10.1080/00219266.2012.716785

Gilbert, J. K. (2008). Visualisation: An emergent field of practice and enquire. In J. K. Gilbert., M. Reiner \& M. Nakhleh (Eds.), Visualisation: Theory and practice in science education (pp. 3-24). Springer. https:/ / doi.org/10.1007/978-1-4020-5267-5

Gilbert, J., Osborne, R., \& Fensham, P. (1982). Children's science and its consequences for teaching. Science Education, 66, 623-633. https://doi.org/10.1002/ sce.3730660412

Golan-Duncan, R., Castro-Faix, M., \& Choi, J. (2016). Informing a learning progression in genetics: Which should be taught first: Mendelian inheritance or the central dogma of molecular biology? International Journal of Science and Mathematics Education, 14, 445-472. https:/ / doi.org /10.1007/s10763-014-9568-3

Griffiths, P., \& Stotz, K. (2013). Genetics and philosophy: An introduction. Cambridge University Press. https://doi.org/10.1017/CBO9780511744082

Jalmo, T., \& Suwandi, T. (2018). Biology education students' mental models on genetic concepts. Journal of Baltic Science Education, 17(3), 474-485. https://doi.org/10.33225/jbse/18.17.474

Kapteijn, M. (1990). The functions of organisational levels in biology for describing and planning biology education. In P. L. Lijnse, R. Licht, W. de Vos, \& A. J. Vaarlo (Eds.), Relating macroscopic phenomena to microscopic particles (pp. 139-150). CDPress.

Knippels, M. C. P. J. (2002). Coping with the abstract and complex nature of genetics in biology education: The yoyo learning and teaching strategy. CD-Press.
Kozma, R. (2003). The material features of multiple representations and their cognitive and social affordances for science understanding. Learning and Instruction, 13(2), 205-226. https:/ / doi.org/10.1016 /S0959-4752(02)00021-X

Kozma, R., \& Russell, J. (2005). Students becoming chemists: Developing representational competence. In J. K. Gilbert (Ed.), Visualisation in science education (pp. 121-145). Springer. https://doi.org/10.1007/1-4020-3613-2_8

Lewis, J., \& Wood-Robinson, C. (2000). Genes, chromosomes, cell division and inheritance: Do students see any relationship? International Journal of Science Education, 22(2), 177-195. https:// doi.org/10.1080/095006900289949

Lewis, J., Leach, J., \& Wood-Robinson, C. (2000a). What's in a cell? Young people's understanding of the genetic relationship between cells, within an individual. Journal of Biological Education, 34(3), 129132.

https:/ / doi.org/10.1080/00219266.2000.9655702

Lewis, J., Leach, J., \& Wood-Robinson, C. (2000b). All in the genes? Young people's understanding of the nature of genes. Journal of Biological Education, 34(2), 74-79.

https:/ / doi.org/10.1080/00219266.2000.9655689

Lewis, J., Leach, J., \& Wood-Robinson, C. (2000c). Chromosomes: The missing link. Young people's understanding of mitosis, meiosis and fertilisation. Journal of Biological Education, 34(3), 189-199. https:/ / doi.org/10.1080/00219266.2000.9655717

Marbach-Ad, G., \& Stavy, R. (2000). Students' cellular and molecular explanations of genetic phenomena. Journal of Biological Education, 34(4), 200-205. https:/ / doi.org/10.1080/00219266.2000.9655718

Pande, P., \& Chandrasekharan, S. (2017). Representational competence: Towards a distributed and embodied cognition account. Studies in Science Education, 53(1), 1-43. https:/ / doi.org/10.1080/03057267.2017.1248627

Prain, V. \& Tytler, R. (2012). Learning through constructing representations in science: A framework of representational construction affordances. International Journal of Science Education, 34(17), 2751-2773. https://doi.org/ 10.1080/09500693.2011.626462

Rotbain, Y., Stavy, R., \& Marbach-Ad, G. (2008). The effect of different molecular models on high school students' conceptions of molecular genetics. Science Education Review, 7(2), 54-69.

Scheid, J., Müller, A., Hettmannsperger, R., \& Schnotz, W. (2018). Representational competence in science education: From theory to assessment. In Kristy L. Daniel (Ed.), Towards a framework for representational competence in science education (pp. 263-277). 
Springer. $\quad$ https://doi.org/10.1007/978-3-31989945-9_13

Schonborn, K., \& Bogeholz, S. (2013). Experts' views on translation across multiple external representations in acquiring biological knowledge bout ecology, genetics, and evolution. In D. F. Treagust \& C-Y. Tsui (Eds.). Multiple representations in biological education (pp. 147-164). Springer. https:/ / doi.org/ 10.1007/978-94-007-4192-8_7

Stewart, J., Cartier, J., \& Passmore, C. (2005). Developing understanding through model-based inquiry. In M. S. Donovan, y J. D. Bransford (Eds.), How students learn: History, mathematics, and science in the classroom (pp. 515-565). The National Academic Press.

Tsui, Chi-Yan., \& Treagust, D. F. (2013). Introduction on multiple representations: The importance in biological education. In D. F. Treagust y Chi-Yan, Tsui (Eds), Multiple representations in biological education (pp. 3-18). Springer. https://doi.org/ 10.1007/978-94-007-4192-8_1

Venville, G., \& Treagust, D. F. (1998). Exploring conceptual change using a multidimensional interpretive framework. Journal of Research in Science Teaching, 35(9), 1031-1055. https:/ / doi.org/ 10.1002/(SICI)1098-2736(199811)35:9<1031::AIDTEA5>3.0.CO;2-E

Wilson, M. (2005). Constructing measures: An item response modelling approach. Lawrence Erlbaum Associates.

Wu, H.-K., \& Puntambekar, S. (2012). Pedagogical affordances of multiple external representations in science processes. Journal of Science Education and Technology, 21(6), 754-767. https:/ / doi.org/10.1007 / s10956-011-9363-7

\section{http://www.ejmste.com}

